\title{
Research on Engineering Leading Talents Training Model
}

\section{Ce ZHANG ${ }^{a,{ }^{*}}$, Song-Lin $\mathrm{GU}^{\mathrm{b}}$, Jia-Nan JIANG ${ }^{\mathrm{c}}$, Dian-Hui $\mathrm{CHU}^{\mathrm{d}}$, Jian-Xiong $\mathrm{LI}^{\mathrm{e}}$ and Wei-Gong $\mathrm{LV}^{\dagger}$}

School of Computer Science and Technology, Harbin Institute of Technology at Weihai, 2 Cultural West Road, 264209 Weihai, Shandong Province, China

zhangce@hitwh.edu.cn, gusonglin828@163.com, susan_jin@163.com, cdh@hitwh.ed.cn, 13561816673@163.com, lwgswl@sina.com

Keywords: Engineering leading talents, Training model, School-enterprise co-education.

\begin{abstract}
Engineering education is an important part of higher education and an important carrier for cultivating high-quality engineering talents. In order to solve the problem of the lack of qualified personnel in engineering leading and topnotch innovation engineering practice ability, we propose a training model for engineering leading talents and calls for engineering education to implement a training program for talented people who are oriented to the development of the future and provide a talent support for industrial restructuring, economic development and social progress. The ELTP training mode is analyzed from 6 transitional angles, including from school to school, from theoretical knowledge to engineering practice, from school resources to enterprise resources, from simple internship experience to comprehensive training experience, from course study or virtual project to real engineering projects and from leadership potential to leadership. The training process is analyzed and five implementation points are given, including student selection and related coursework, engineering learning training, school-enterprise co-education, project practice, graduation design and employment recommendation. Finally, we draw the conclusion from the target that ELTP can be achieved.
\end{abstract}

\section{Introduction}

The graduates of engineering colleges are lacking in engineering capabilities, organizational skills, leadership skills and sense of responsibility. This is both an area where students are eager to improve themselves and the common aspiration of businesses.

Engineering Leading Talents Program(ELTP) intends to train innovative engineering talents in engineering education at universities to meet the needs of engineering leaders in the premium end of industry and shorten the gap between talent cultivation in campus education and business needs, so that we can create and explore the environment for effective growth of engineering leaders, training mode and education mechanism. ELTP is a new way of education and an important aspect of engineering education reform. It is also a new mode of training talents in schools and industries and enterprises.

Students participating in ELTP can accept the guidance and training of business mentors, and can truly experience the business management and engineering research and development process of industry. They can practice the campus theory in the real enterprise environment and the project scenario. An important practice platform and valuable chance are provided for the development goal with engineering leadership as the core.

\section{Domestic and Foreign Status}

Engineering leading talent training has become an important talent training mission of world-class university, especially the first-class engineering college or engineering education.

The proposed MIT program is based on the American Competitiveness Initiative(ACI $)^{[1]}$ announced by the U.S. government in 2006, hoping that the United States will retain its leading 
position in talents, creativity and basic research with enhanced research investment, education quality and talent training force. Entering the era of globalized knowledge economy in the new century and the Internet age, MIT further defined its goal of personnel training as "cultivating knowledgeable, distinctive and creative leading talents who are capable of leading the next century". Among the specific training objectives of its colleges, the training of researching or engineering leading talents is also an important goal.

On the cultivation of engineering leading talents, the United States places more emphasis on the training of competitive talents under the guidance of technological change ${ }^{[1-6]}$, reflecting the adjustment of personnel training programs in college education under the overall education system ${ }^{[7-9]}$. The United States is the first country in the world to propose a shift from theoretical research in the traditional university to talented personnel in engineering innovation. In particular, during Carl Taylor Compton's tenure as the ninth president of $\mathrm{MIT}^{[9]}$, he put forward the reform that emphasized the needs of industries, strengthened the study of industrial innovation fosters the development of outstanding engineering leading talents, which greatly accelerated the process of the training of engineering leading talents.

In China, many high-level universities have carried out ELTP-related practices ${ }^{[10-12]}$, such as Tsinghua University leadership training, Harbin Institute of Technology ELTP implementation, Beijing University of Aeronautics and Astronautics Engineers, Northwestern Polytechnic University "5438 (Based on 5 combinations, 4 focused, 3 platforms set up and 8 initiatives implemented) "model, Renmin University of China Business School to develop successful leadership programs and so on. These practices not only innovated the training mode of ELTP, but also explored a lot of practical measures and achieved initial results. In addition, China has put forward specific encouragement policies, aiming at the urgent needs of engineering leading talents in the premium end of industries $^{[13-14]}$. We hope to attract more high-level talents with engineering innovation and leadership capabilities to drive and upgrade the development of industries in the region.

ELTP is to develop and train the excellent students with leading potential to further enhance their innovative capabilities and engineering leadership so as to cultivate top-notch engineering innovation talents with international competitiveness.

\section{Training Model Analysis}

ELTP aims to give engineering leadership training to outstanding students with leading potential. The training model of project implementation plan can be summed up as follows: comprehensive selection, combination of course study and engineering practice, cooperation of school with enterprise, consistency education from undergraduate to master, and self-cultivation.

First of all, we should select outstanding students with excellent academic performance and leading potential as the training target. In their senior grades, their theoretical study of engineering leadership and engineering -oriented learning should be strengthened so as to cultivate students' engineering leading qualities. Then the students will be arranged to enter the enterprises or the research institutes for practical training under the guidance of the top management. The consistency education from undergraduate to master will be implemented jointly by the academic affairs office and the college. Individualized training programs will be formulated for students enrolled in the program based on the characteristics of students by school and enterprise guidance teachers, and targeted guidance will be provided to teach students in accordance with their aptitudes. Figure 1 shows the ELTP training mode. 


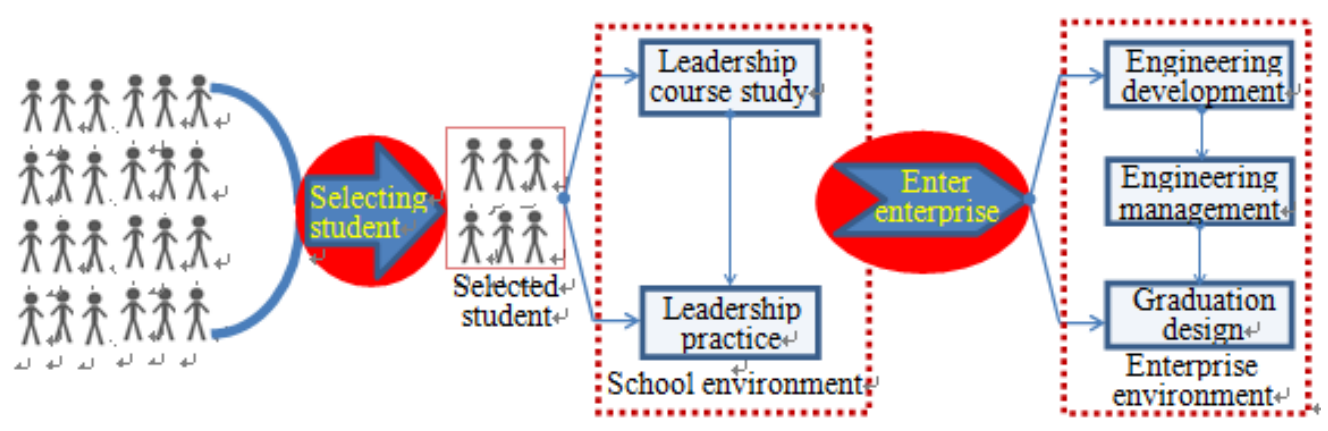

Figure.1. ELTP Training model

It can be seen that the implementation of ELTP will bring transformation and leap as follows:

From theoretical knowledge to engineering practice - professional courses, talent management courses and enterprise co-construction courses should be completed and engineering leading training should be conducted to enter into enterprises to conduct engineering-centered $\mathrm{R} \& \mathrm{D}$ and management practices;

From inside the school to outside the school - students should not only complete fixed course study and training in the school, but more importantly, enter the school to carry out internship practice;

From school resources to enterprise resources - schools and businesses provide a variety of resources to work together to build the environment for engineering leading training;

(4) From purely internship experience to comprehensive training experience - In the traditional internship, students enter the enterprise for internship with project participation as the mainstay; engineering leading talents pay more attention to project planning, project management, interaction with top management supervisors, and complete the source Graduation project from real project;

(5) From course study or virtual project to real project - The school mainly focuses on course study, experiment and course design. Students enter the enterprise to fully face the real project. The containing realism, sense of responsibility and accomplishment are unmatched by study inside school;

(6) From leadership potential to owning leadership — The project requires the selected students to have some leadership potential. After the in-school study and practice and the practice of corporate internship, the students will complete the transition to certain leadership.

ELTP will actively implement the education philosophy of combining campus education with enterprise education and combining curriculum learning with engineering practice. Then education-oriented and competency-driver education methods will be gradually established. The curriculum-based learning and project-based learning methods will be implemented to fully develop students' engineering innovation and leadership, and constantly improve the undergraduate talent training quality and level.

It has become an important content in engineering education today to promote the implementation of ELTP, including building a curriculum content system integrating theory and practice, deepening the cooperation between universities and enterprises, exploring and improving the training mode, and strengthening students’ practical ability, innovation ability and engineering leadership.

\section{Training Process and Implement Program Points}

When ELTP is implemented, a number of outstanding students will be sent to enter the program and business leadership internship every year. We will give full play to the comprehensive training results of campus learning and corporate internship, and improve the engineering practice innovation and engineering leadership of students who are both good at science and technology. Figure 2 shows the ELTP basic training process. 


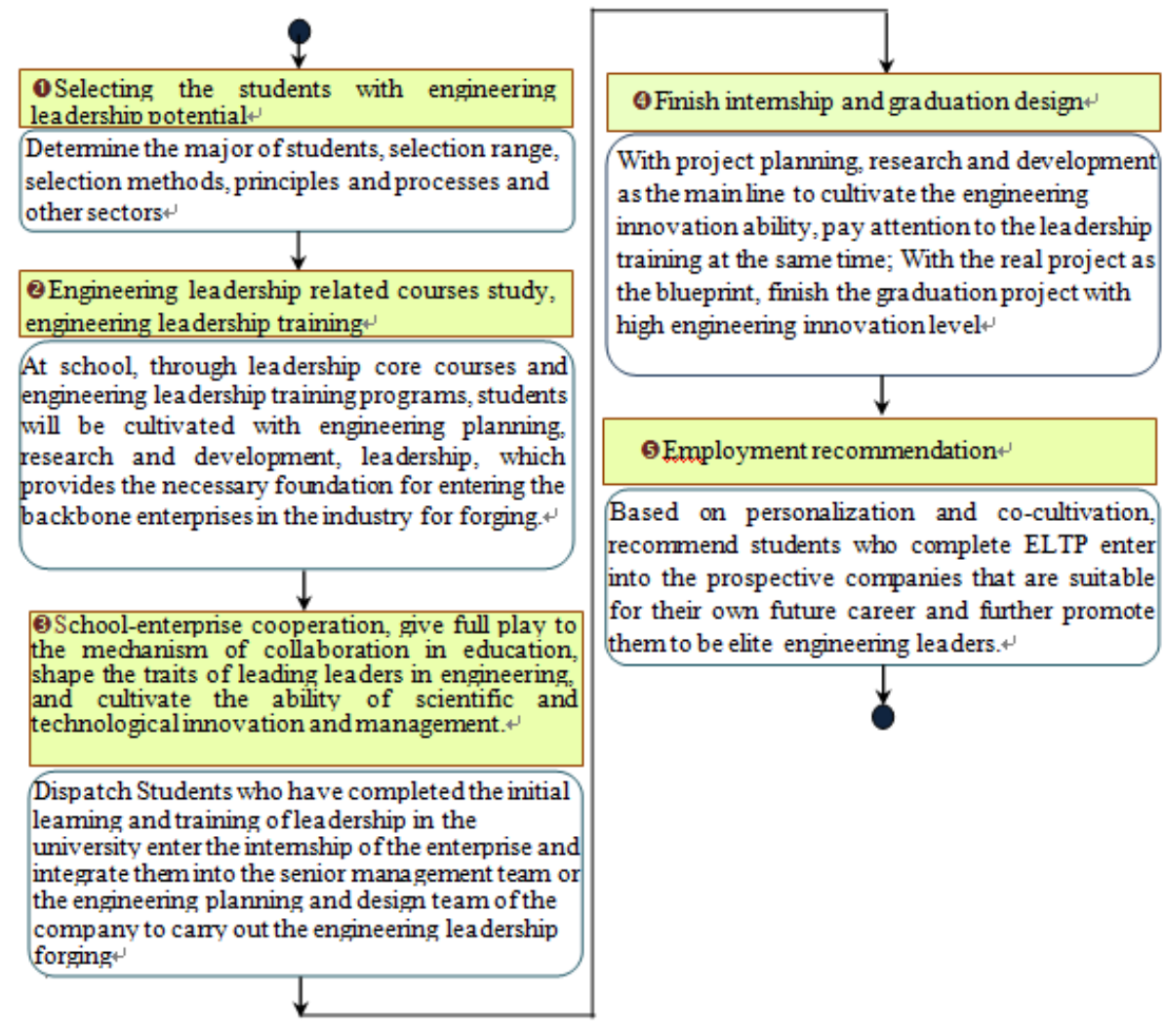

Figure.2.ELTP basic training process

\section{Student Selection and Related Courses Study}

For the selected students, this project will set up special engineering leadership-related courses and employ outstanding management teachers to teach leadership related courses (currently 4), including classical theories of management and case studies, leadership and communication, project management, organizational behavior and team building and some other courses. On this basis, we will rely on the college's strong scientific research strengths to open courses in major and major systems related to this major. At the same time, we will also cooperate with enterprises and invite senior engineers in engineering research and development or management to jointly set up courses in discipline-specific fields or industry integrated innovation training, engineering leading training courses. These courses will be offered to juniors, seniors for elective participation.

\section{Engineering Study Training}

Through the implementation of the first grade project, the second / third year professional design project curriculum, the college students' innovation and entrepreneurship training programs, science and technology competitions and other aspects of the project-oriented learning process, students can initially develop communication, expression and leadership skills. On this basis, we will further strengthen the learning and training of project participants in the project. In the seventh semester, we will arrange for students to complete a project or engineering leadership training project equivalent to graduation design, with the guidance of a high level of professors and their teams, and provide the appropriate support conditions. In the eighth semester, students will be arranged for business internships, through participation in practical projects to improve engineering capabilities and leadership.

\section{School-Enterprise Co-Education}

To promote the pilot ELTP, it is necessary to deepen the cooperation between schools and enterprises, further improve the model of enterprise internship training, build a better platform for practice and education, and provide more suitable conditions for the growth of top-notch innovative engineering 
leading talents so as to improve students' practical ability, innovation ability and engineering leadership.

The cooperation between school and enterprise is the key link of this plan. Based on the resources and experience, we have accumulated over the years in the construction of practice base, production, research institutes, graduation recruitment, etc. We will actively cooperate with industry leaders (especially those in the industry large-scale backbone enterprises, multinational corporations, research institutes, etc.) to set up college students' of-campus practical education bases or student intern bases. We will send outstanding selected students to the enterprise internship, enter the enterprise management team or engineering planning and design team. Under the guidance of senior staff, students should complete the graduation project or graduate engineering practice and focus on student leadership training. As an important collaborative management $\mathrm{B}$, we will work with these well-known companies to build related courses, engineering research and development and leadership training teaching and practice. We will also send some teachers to the cooperative enterprises for engineering skill training and practical exercise to help enterprises do a good job of engineering leading talents and management.

\section{Program Practice and Graduation Design}

Students are required to participate in the planning, design, development and implementation of the real project of the enterprise with the awareness and attitude of the real employees, focusing on the organization and coordination ability of the project. Students have to interact with the leaders of the enterprises in the implementation of the whole process to learn the business management, and enable students to get the integration of science and technology innovation and leadership training to cultivate engineering talent with management skills. When it's time for the school's required time for graduation design, students are required to consult with the enterprise instructors and school instructors about it. The content should originate from the actual project of the enterprise and must have the dual requirements of innovation and workload so that the students can finish the graduation project. The process of graduation design will also become the process of training engineering innovation.

\section{Employment Recommendation}

When the implementation of ELTP is nearing completion, based on the many established internship bases, production and research base and other resources, the college will attach great importance to the employment recommendation of students participating in the project and strive to recommend these outstanding students to the relevant important positions of enterprises or research institutes that will benefit their future career development, so that they will quickly become engineering leading talents with scientific and technological innovation and management talent.

\section{Conclusion}

ELTP supports the implementation of this program in all respects from the aspects of course teaching, engineering leading training, research projects and the construction of a key school-enterprise cooperation base. ELTP is expected to create an effective environment suitable for the cultivation of high-level composite talents in engineering leadership, and provide convenient conditions for rapid growth so that selected students can better grasp the theoretical knowledge of engineering leadership and have a certain innovation in engineering research and development, and the basic ability of business operation and maintenance management. Through the implementation of ELTP can achieve the goal is to train top-notch talent for premium computer industry with practical ability, innovation and engineering leadership. With school-enterprise training as a carrier, the implementation of double tutorial system is a multi-process and multi-participatory cross-collaboration integrated implementation of educating system and collaborative management mechanism. 


\section{Acknowledgement}

In this paper, the research was sponsored by the 2016 Research and Practice on Engineering Leading Talent Training Mode for Engineering Top-notch Talents of Shandong Province Undergraduate Teaching Reform Research Project (B2016M016), the 2017 project of collaborative education for production-learning cooperation of the Ministry of Education, "Laboratory of IoT Labs focusing on cultivating complex engineering problem-solving capabilities", the 2016 Shandong Province Graduate Education Innovation Project Special Project "Multidimensional Education Quality for Professional Degree Graduate Students Evaluation System (SDYZ1603) ", and Research Project "Research and Practice of Internet of Things Talents Training Model" of Harbin Institute of Technology at Weihai (BK201602).

\section{References}

[1] Lei H, Crawley E. Develop Engineering Leadership to Lead the Development of the World - MIT Gordon Engineering Leadership Program Overview[J]. Tsinghua University Education Research, 2010, 31(1): 77-83.

[2] Cui J, Wang X. Develop Engineering Leader: Engineering Leadership Education at MIT[J]. Higher science education, 2010(6): 30-35.

[3] Lei Q, Gong X. An Analysis of the Features of the Project-based Talents Training Programs for Undergraduate Stage - A Case Study of Gordon-MIT Project Leadership Program[J]. Journal of Beijing University of Aeronautics and Astronautics (Social Sciences Edition), 2010, 23(1): 108-113.

[4] Leaders for Global Operations, LGO. http://cee.mit.edu/node/2833. 2009-11-30.

[5] Kalkhoff M, Athreya K S, Rover D, et al. Work in progress-highlights and challenges of a student driven co-curricular leadership program//Frontiers in Education Conference, 2009. FIE09, 39th IEEE. IEEE, 2009: 1 2.

[6] Schuhmann R J. Engineering leadership education: the search for definition and a curricular approach[J]. Journal of Stem Education, 2010(11): 61-69.

[7] Athreya K S, Kalkhoff M, McGrath G, et al. Engineering Leadership Program: Tracking Leadership Development of Students using Personalized Portfolios//38th ASEE/IEEE Frontiers in Education Conference, 2008.

[8] Cui W X, Zhang D. Student Leadership Project at the University of Maryland[J]. World Education Information, 2013(11): 18-23.

[9] Zhou J, Guo A H. Engineering Leadership Training in Higher Education[J]. Computer education, 2013(5): 106-110.

[10] Zhong M. Leadership Education in American Universities and Its Enlightenment[J]. Higher Engineering Education Research, 2008(6): 115-118.

[11] Liu Q. From First Class Scientists to Leading Leaders - Reflections on Compton, President of Massachusetts Institute of Technology[J]. University Education Management, 2014, 8(2): 17-22.

[12] Liang G M. A Comparative Study of Engineering Leadership Training in USA and Russia[D]. Harbin Institute of Technology, 2013.

[13] http://www.bdasme.org/zcxqzc/5463.jhtml

[14] http://www.wtoutiao.com/p/hf3yTg.html 